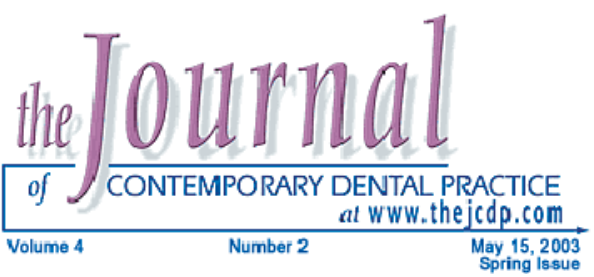

\title{
Effects of a Betaine-containing Toothpaste on Subjective Symptoms of Dry Mouth: A Randomized Clinical Trial
}

Irma Rantanen, DDS; Jorma Tenovuo, DDS, PhD, Prof.;

Kaisu Pienihäkkinen, DDS, PhD; Eva Söderling, PhD, MSe

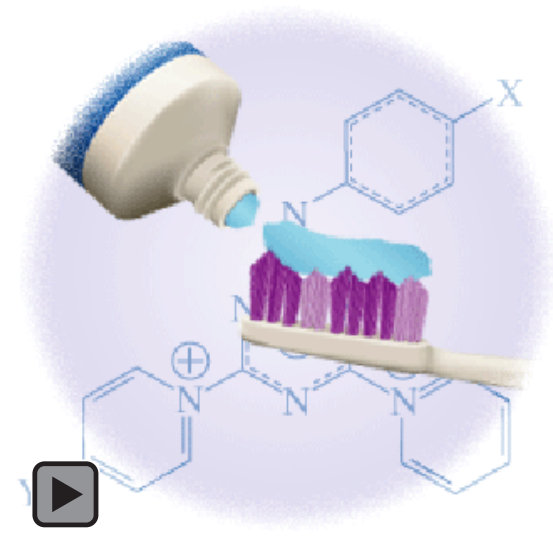

Abstract

Our aim was to study the effects of mildly flavoured sodium lauryl sulphate (SLS)-containing and detergent-free toothpastes with and without betaine (BET) on subjective symptoms of dry mouth in a randomised clinical trial. $\mathrm{BET}$ is an osmoprotectant that reacts with molecules to supply the surface with a water coating that protects cells from surfactants. Twenty-seven xerostomic patients and 18 healthy controls took part in the randomised, double-blind clinical trial with a crossover design. Three mildly flavoured toothpastes: (1) $4 \%$ BET, (2) $1 \%$ SLS and $4 \%$ BET, and (3) $1 \%$ SLS were used for six weeks each. The reference or washout paste contained neither SLS nor BET. The subjects' dental appointments were at the beginning of the trial and before and after the use of each toothpaste. At each appointment, the subjects were interviewed about subjective sensations of dry mouth (Visual Assessment Scoring (VAS) Index). The subjects did not report any adverse effects in connection with the use of the toothpastes. The VAS scores for lip dryness and eating difficulties were significantly lower for the BET paste (lip dryness: BET<BET+SLS; $p<0.005$ and eating difficulties: BET $<B E T+S L S ; p=0.02 ; B E T<$ reference; $p=0.003$ ). The BET paste relieved dry mouth symptoms in $44 \%$ of the xerostomic patients, the corresponding figures for the other pastes being BET+SLS 22\% ( $p=0.002$ as compared with BET), SLS 18\% $(p=0.022)$, and reference $7 \%(p=0.000)$. In conclusion, all the mildly flavoured toothpastes used in this study were well accepted by the xerostomic subjects. Thus, other toothpaste components may be more mucosa-irritating than just SLS, or else they enhance the effect of SLS. The detergent-free, BET-containing toothpaste appeared to be associated with relief of some symptoms of dry mouth.

Keywords: Toothpaste, betaine, BET, sodium lauryl sulphate, SLS, dry mouth, xerostomia, clinical trial, Sjögren's syndrome

Citation: Rantanen I, Tenovuo J, Pienihäkkinen K, et. al. Effects of a betaine-containing toothpaste on subjective symptoms of dry mouth, a randomised clinical trial. J Contemp Dent Pract 2003 May;(4)2:011-023.

(C) Seer Publishing 


\section{Introduction}

Xerostomia is a term used to describe the subjective (feeling) symptoms of a dry mouth. The objective signs of dry mouth have been categorised as salivary gland hypofunction. ${ }^{1,2}$ Salivary gland hypofunction consists of different aspects such as xerostomia (feeling of dry mouth), hyposalivation (diminished salivary secretion), and altered saliva composition. The terms are often used interchangeably which adds to the confusion. The prevalence of these signs and symptoms have been measured and described differently in different studies. The prevalence of xerostomia is estimated to vary from 6.2 to $46 \%$ of the population. ${ }^{2 \cdot 4}$ Dry and/or sensitive mouth (both xerostomia and salivary gland hypofunction) can be due to side effects of various drugs, systemic diseases (especially autoimmune disorders), and malignancies affecting salivary gland with possible operations and radiation-therapy. ${ }^{5}$ In the United States, over one million people suffer from Sjögren's syndrome, an autoimmune disorder affecting the salivary gland function. ${ }^{6}$ In Finland, around 22,000 Finnish citizens (approximately $0.5 \%$ of the population), suffer from primary Sjögren's syndrome. ${ }^{7}$ Reduced saliva secretion often causes many unpleasant subjective symptoms, such as alterations in taste and burning sensation. ${ }^{5,8-11}$ The dry oral mucosa can be more sensitive to irritative compounds in dental care products than healthy mucosa. ${ }^{12}$ Talking and swallowing may become difficult and the risk of dental caries, periodontal diseases, and mucous inflammations increases. ${ }^{13-15}$

The most commonly used synthetic detergent in toothpastes, sodium lauryl sulphate (SLS), emulsifies the plaque deposits and dissolves lipophilic substances in toothpastes and mouthwashes. ${ }^{16}$ The detergent in toothpaste foams when brushing and reduces surface tension enhancing the toothpaste's penetration into interdental tooth surfaces. This prolongs the toothpaste's retention on teeth and facilitates the contact of fluoride compounds with the dentition for a longer time. Toothpaste detergents also inhibit plaque bacteria and help with the mechanical removal of plaque. ${ }^{17}$ On the other hand, the detergents, and especially SLS, are known to cause untoward changes both in oral mucosa and on skin. ${ }^{18,19,20-23}$ It is suggested toothpaste compositions should contain less irritating detergents. ${ }^{24}$

Betaine (BET), also known as trimethylglycine or glycinebetaine, is a natural product, which is chromatographically separated from sugar beet molasses during sugar production. It has been found to act as an osmoprotectant in bacteria, plants, and animals, and it protects cell components against harsh conditions in vitro. ${ }^{25}$ BET reduces the skin-irritating properties of detergents in cosmetics. ${ }^{26,27}$ It has also reduced the irritating effect of SLS-containing toothpaste in skin exposure tests. ${ }^{28}$ BET reacts with molecules to supply the surface with a water coating that protects cells from surfactants. In our earlier study, subjects suffering from xerostomia preferred a combination SLS-BET toothpaste to a regular toothpaste containing only SLS. ${ }^{29}$ The BET-containing toothpaste also appeared to relieve subjective symptoms of dry mouth. ${ }^{29}$

The aim in this study was to compare the effects of mildly flavoured SLS-containing as well as detergent-free toothpastes with and without BET on xerostomic symptoms in a longitudinal randomised, double-blind clinical trial.

\section{Material and Methods}

\section{Subjects}

Twenty-seven volunteers, 25 women and 2 men with a mean age of $52.9 \pm 13.1$ years, participated in the study group. They all suffered from subjective symptoms of dry mouth. All these xerostomic subjects had one or more systemic diseases; the most common diagnosis being Sjögren's syndrome (15 subjects). The xerostomic subjects also used medications on a regular basis; the mean number of drugs used daily was 2.5 (range $0-8$ ). Seventeen subjects in the xerostomic group reported they suffered from allergies. Twenty-five matched controls (24 women and 1 man) without any symptoms of dry mouth were recruited. The mean age of the control subjects was $52.4 \pm 17.2$ years.

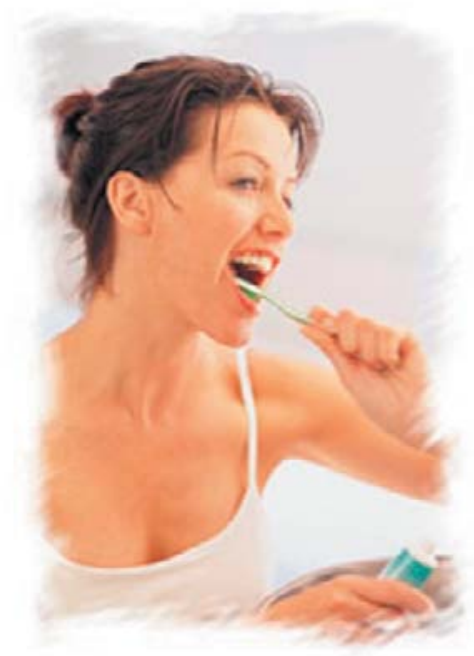


Thirteen subjects in the control group reported 1-2 chronic diseases, and 15 used some medication (most often hormonal products with a mean number of 0.84 drugs used daily, range $0-3$ ). Neither the diseases nor the medication were known to affect saliva secretion. Eleven of the control subjects reported allergies. In the xerostomic group, one male subject interrupted the study for personal reasons. In the control group, seven female subjects interrupted the study, the main reason being the tastlessness of the toothpastes. No one interrupted the study due to adverse effects connected with the use of the toothpastes.

All subjects signed an informed consent form. The Ethical Committee of the Faculty of Medicine, University of Turku, approved the study protocol.

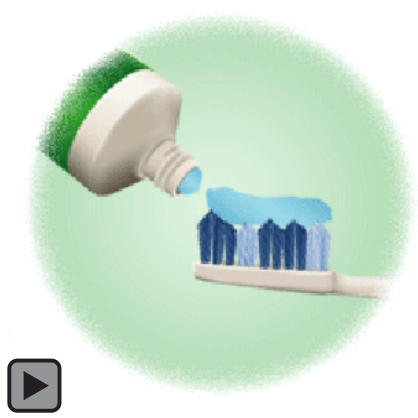

\section{Study Design}

The study was a double-blind, randomised and controlled clinical trial with a crossover design. The subjects in both xerostomic and control groups were randomly allocated to use each of the three test toothpastes in a predetermined sequence for six weeks. Each phase was preceded by a six-week washout period during which the reference paste was used to assure elimination of any residual test toothpaste. It was also used at the end of the trial. Table 1 shows the schematic presentation of the study design.

The first appointment was made at the beginning of the trial, before the use of the reference toothpaste. During this appointment the subjects received information on the study, signed the consent form, and underwent a baseline examination. The examination included the following:

- An interview about general health

- A review of medications and allergies

- Identification of oral hygiene habits

- An evaluation of subjective dry mouth symptoms (Table 2)

- An assessment of plaque quantity

- A visual inspection of oral mucosa

In addition to the examination, changes in symptoms of oral dryness and also changes in general health, medication, or oral hygiene habits were recorded. No new systemic diseases or drugs known to affect saliva secretion or mucosal sensitivity were reported in either group during the study.

At the baseline examination, the participants were asked to brush their teeth twice a day (two minutes at a time), dispense the toothpaste along the length of the tips of the toothbrush bristles (approximately $1.5 \mathrm{~g}$ ), and refrain from brushing in the morning before the appointment. They were also instructed to refrain from eating and drinking for at least one hour prior to each appointment. The toothbrushes were given to the participants and replaced with new ones when needed (approximately three toothbrushes/participant). The participants were advised not to make any

Table 1. Schematic illustration of the study design. The toothpastes with BET, BET+SLS and SLS were number coded 1-3, and used in random order for six weeks each. The washout periods with the reference paste also lasted six weeks.

\section{Baseline \\ evaluation}

\begin{tabular}{ll}
\hline & Reference paste \\
\hline Appointment & \\
\hline Appointment & paste $1-3$ \\
\hline & Reference paste \\
\hline Appointment & \\
\hline Appointment & paste 1-3 \\
\hline Appointment & Reference paste \\
\hline Appointment & paste 1-3 \\
\hline Final \\
appointment
\end{tabular}

Table 2. The VAS-scored symptoms of xerostomia.
Dry mouth during daytime Need to drink during daytime Dry mouth during nighttime Need to drink during nighttime Oral pain and discomfort Lip dryness Swallowing difficulties (due to dryness) Eating difficulties (due to dryness) Speaking difficulties (due to dryness) 
changes in their use of dental hygiene products, and if they were obliged to do so, to report all changes in their daily habits. Antimicrobial dental hygiene products were not recommended to be used during the trial.

\section{Study Toothpastes}

The three experimental toothpastes used in the study in a normal toothpaste base were:

1. $4 \%$ BET (Betafin BP, Finnfeeds, Naantali, Finland)

2. $1 \%$ SLS (SLS; Texapon K 12, Henkel, KOGA, Düsseldorf, Germany) with $4 \%$ BET

3. $1 \%$ SLS

The composition of the toothpastes is listed in Table 3. The reference paste, which contained neither BET nor SLS, was used during washout periods between the test periods. The Salutem Company of Turku, Finland, prepared all the

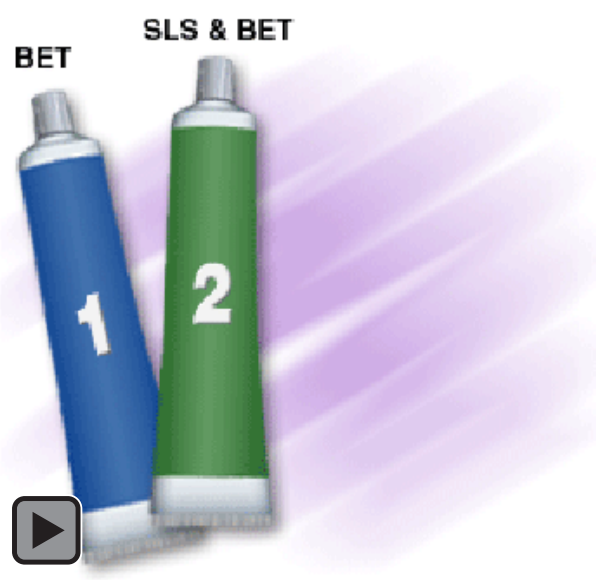

toothpastes for this study. The $\mathrm{pH}$ of the test toothpastes was 6.7. The toothpastes were numbercoded to ensure a double-blind design.

\section{Collection of Saliva and Assessment of Plaque and Oral Mucosa}

Unstimulated whole saliva (UWS) was collected two to three times from the xerostomic subjects and once from the controls during the 10-month study.

The amount of dental plaque was assessed with Sillness-Löe ${ }^{30}$ and Quiqley-Hein ${ }^{31}$-methods from the second upper and lower incisors of the test person at each appointment.

The appearance of oral mucosa was examined visually for any alterations at each appointment.

\section{Evaluation Methods}

The Visual Assessment Scoring Index (VAS, scale 0 -10) was used to assess the subjective symptoms of dry mouth at every appointment (Table 2). The participants were asked about changes in symptoms (increase, no change, decrease) at each appointment. The study toothpastes were compared with the reference paste and the reference paste with the previous study toothpaste. Subjects were also asked to evaluate all the pastes in general using the same 0 to 10 VAS-scale. The preference for each toothpaste was discussed after the use of all toothpastes at the end of the trial. The opinion of the subjects on the taste and composition of the toothpastes as well as on adverse effects like oral pain and ulcers were recorded at each appointment.

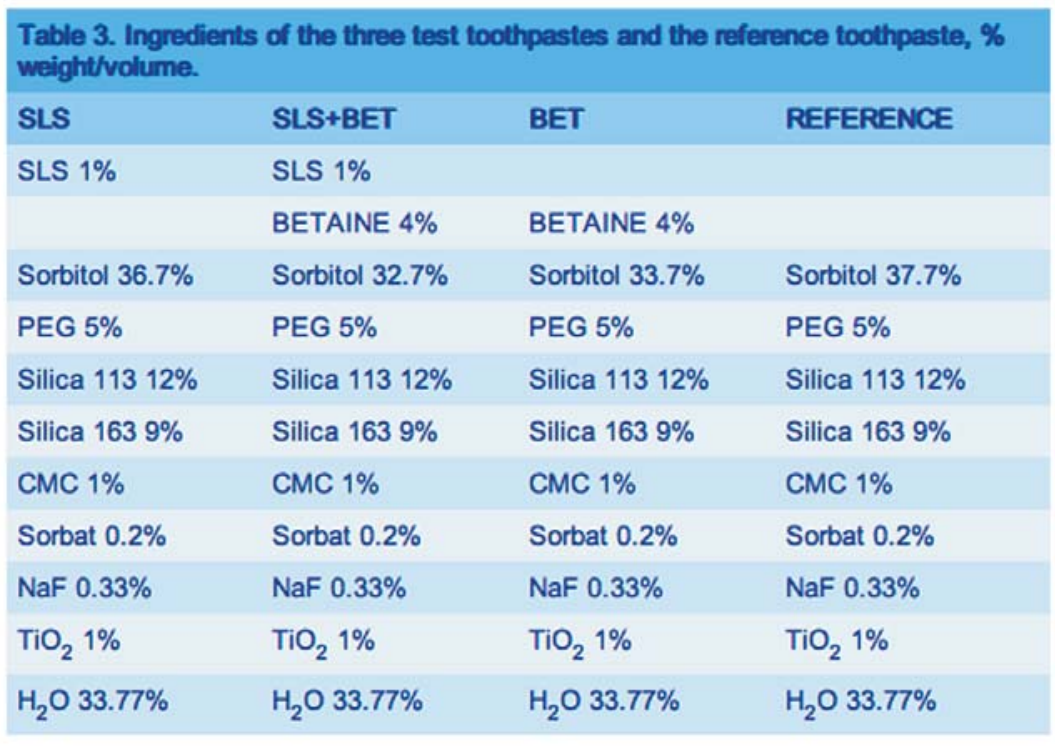




\section{Statistics}

The statistical evaluations of the variables recorded on the VAS scale as well as the evaluations of the pastes were conducted using parametric repeated measurements analysis of variance (RANOVA). Only in the case of statistical significance, were pairwise comparisons between the toothpastes done with paired Student's t-test and between the groups with Student's t-test for independent variables. The changes in symptoms (increase, no change, decrease) and in evaluation of relief of oral dryness were tested with the nonparametric Friedman's test. A non-parametric, pairwise Wilcoxon test was used to test the paired differences in changes and in relief evaluation within the two groups. The differences in plaque indices were tested with the Pearson Chi-square test. The level of statistical significance was set at $<0.05$. For the statistics, we used the SPSS 10.0 software program.

\section{Results}

\section{Salivary Flow Rate, Amount of Plaque, and Mucosal Appearance}

In the xerostomic group, the mean flow rate of UWS was $0.17 \pm 0.16 \mathrm{ml} / \mathrm{min}$. The UWS was very low $(<0.1 \mathrm{ml} / \mathrm{min})$ in 8 subjects, low $(0.1-0.25 \mathrm{ml} /$ $\mathrm{min})$ in 14 subjects, and normal $(>0.25 \mathrm{ml} / \mathrm{min})$ in 5 subjects in the xerostomic group. In the control group, the mean UWS was $0.67 \pm 0.37 \mathrm{ml} / \mathrm{min}$. Four subjects in the control group had low UWS but no subjective symptoms of oral dryness. The UWS was significantly higher in the control group than in the xerostomic group $(p=0.004)$.

The plaque indices did not differ between the xerostomic and control groups during the study, not even when the subjects with very low saliva secretion and the control subjects were compared. Within the groups, no significant differences were detected in the plaque indices in relation to any of the toothpastes.

All xerostomic and control subjects had macroscopically normal oral mucosa, although the mucosal dryness did appear as pale oral mucosa in some subjects with hyposalivation. However, we did not observe any thinned or atrophic mucosa or depapillated tongue surfaces in any of the subjects. The use of the test toothpastes or the reference paste was not associated with any visible alterations in the appearance of the oral mucosa.

\section{Subjective Symptoms of Dry Mouth}

During the whole study, the xerostomic group showed significantly higher $(p<0.000)$ VAS scored symptoms of dry mouth than the control group. The symptoms did not differ significantly between the subjects with low or very low UWS and all subjects in the xerostomic group. Therefore, all xerostomic subjects were pooled in the statistical analyses.

Within the xerostomic group, the highest VAS scores, indicating on average the strongest subjective sensation of dry mouth, were recorded for lip dryness $(p<0.008)$. The VAS scores for lip dryness were significantly lower after the use of the BET paste than after the use of the BET+SLS paste $(p=0.005)$. The SLS, BET+SLS, and reference toothpastes had comparable levels in mean VAS scores (Figure 1). Also, in relation to eating difficulties within the xerostomic group, the BET paste showed significantly lower VAS scores than the BET+SLS toothpaste $(p=0.02)$ and the reference toothpaste $(p=0.03)$. No other significant differences were seen between the toothpastes within the xerostomic or the control group.

No significant differences within the xerostomic and control groups were detected when the subjects were interviewed about changes in dry mouth symptoms after use of each toothpaste.

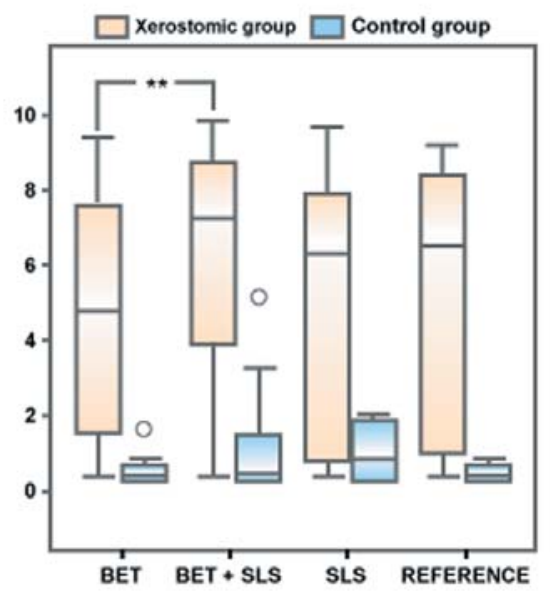

Figure 1. Lip dryness in the xerostomic and control groups after the use of the three experimental toothpastes and the reference paste. BET: $4 \%$ betaine; $B E T+$ SLS: $4 \%$ betaine $+1 \%$ sodium lauryl sulphate; SLS $1 \%$ sodium lauryl sulphate. The boxplots show means, $95 \%$ confidence intervals of means and the standard deviations of VAS scores; scale 0-10 (zero means no dryness, ten utmost dryness). Xerostomic group; $n=27$ and control group; $n=18$. ${ }^{* \star} p<0.01$. 0 Marks an outlier. 


\section{Overall Evaluation of the Toothpastes}

When the toothpastes were evaluated using the VAS scale, no significant differences between any of the used pastes were detected within the xerostomic or control groups (Figure 2). When the xerostomic and the control groups were compared, however, the xerostomic group gave a significantly lower estimate for the SLS paste than the control group (Figure 2, $p=0.03$ ).

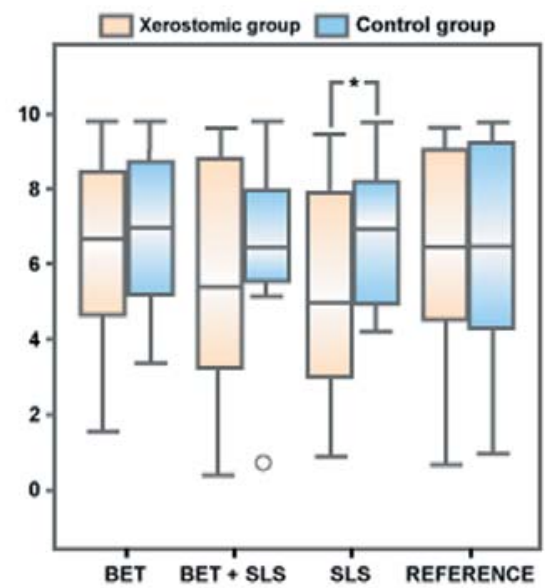

Figure 2. Overall evaluation of the toothpastes by the xerostomic and control subjects, BET: $4 \%$ betaine; BET+SLS: $4 \%$ betaine $+1 \%$ sodium lauryl sulphate; SLS: $1 \%$ sodium layryl sulphate. The boxplots show means, $95 \%$ confidence intervals of means, and the standard deviations of VAS scores; scale 0-10 (zero means not acceptable, ten excellent). Xerostomic group; $n=27$ and control group; $n=18$. ${ }^{*} p<0.05$. 0 Marks an outlier.

The xerostomic and control subjects were interviewed at the end of the trial on their opinions of the different toothpastes. The BET paste relieved dry mouth symptoms even for several hours in the xerostomic group in $44 \%$ of subjects. The BET+SLS paste relieved the symptoms in $22 \%$ ( $p$ $=0.002$ as compared with BET), the SLS paste in $18.5 \%(p=0.022)$, and the reference paste in $7.4 \%(p=0.000)$.

No adverse effects such as aphtous ulcers were reported for the use of the test toothpastes in either the xerostomic or the control group, and no one discontinued the study due to adverse effects associated with any toothpaste. Even the eight xerostomic subjects with very low saliva secretion did not report any adverse effects in association with the use of the pastes. Only one of these subjects with practically no saliva secretion at all experienced some mucosal irritation with all the toothpastes used. About a half of both the xerostomic and control subjects found the composition of the toothpastes suitable. More than one third of the subjects in both the xerostomic group and the control group found the taste of the toothpastes agreeable. However, in the control group, the main reason for interrupting the study was the bland taste of the toothpastes.

\section{Discussion}

To our knowledge this is the first carefully controlled clinical toothpaste study with crossover design in xerostomic subjects. We could not verify the earlier suggestions on the mucosa-irritating effects of the SLS-containing toothpastes. In our study, the mildly tasting $1 \%$ SLS formula was not associated with adverse effects such as mucosal irritation or aphtous ulcers, even among the eight xerostomic subjects with very low salivary flow. However, some SLS-associated differences between the groups were detected: the xerostomic subjects gave a lower estimation for the SLS paste than the control subjects. Generally, all four toothpaste formulas used in this study were well accepted by all subjects participating in the study. Thus, our results suggest that other toothpaste components, such as flavours, may be more mucosa-irritating than SLS.

Regular products for oral hygiene often irritate the dry mouth. This is why mildly tasting special products have been developed for persons suffering from a dry or sensitive mouth. Toothpastes contain a number of substances which irritate even the healthy mucosa and, therefore, it is not a surprise they irritate the mouth in xerostomic subjects. Xerostomic patients show increased retention times of oral hygiene product components ${ }^{32}$, which enhances their possible irritating properties. Flavouring and colouring agents and preservatives may also cause contact allergy on the oral mucosa. ${ }^{33}$ Furthermore, ingredients used in special toothpastes

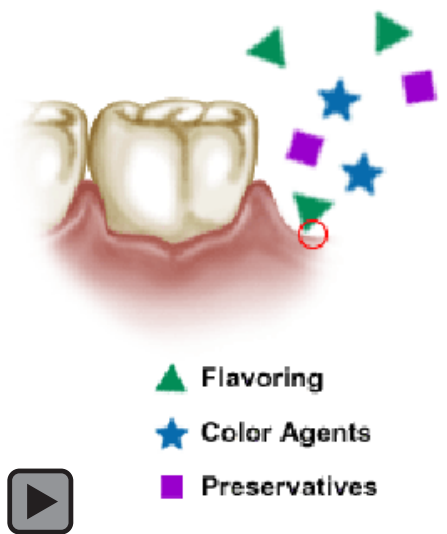
such as tartar-controlling agel ıs Ilave veen reported to irritate the oral mucosa. ${ }^{34}$ The agents considered to be the main irritants in toothpastes are the detergents, especially SLS. ${ }^{18-20}$ It is well known that SLS is an irritant also to skin. ${ }^{21-23}$ Exaggerated study models employing mouthwashes with high SLS-concentrations or exposure of the 
oral mucosa to SLS using capsplints have been shown to induce mucosal desquamation. ${ }^{18,19}$ It has also been suggested the use of SLS-free toothpaste reduces the incidence of recurrent aphtous ulcers $^{24,35}$, even though a study showing no effect of a SLS toothpaste on the ulcer pattern has also been published. ${ }^{36}$ The comparison of our findings to the earlier ones is difficult due to the lack of information on brushing time and amount of toothpaste used in the earlier studies. However, the SLS concentration of our experimental toothpaste corresponds well with SLS concentrations used generally in regular commercial toothpastes in Europe and North America. ${ }^{37}$

$B E T$ is a methyl donor which may be one of the mechanisms by which it protects cells from surfactants. ${ }^{25}$ BET is also an osmoprotectant ${ }^{25}$, a property which could be beneficial in oral hygiene products for xerostomic patients. In skin tests, the irritation-alleviating effects of BET have been shown for BET-SLS solutions and BET-SLS toothpaste (Nicander). ${ }^{28}$ We have shown earlier that subjects suffering from xerostomia preferred a BET-SLS toothpaste over a regular SLS paste. ${ }^{29}$ The BET-containing paste was also reported to alleviate symptoms of dry mouth. ${ }^{29}$ However, when we tested different combinations of BET and SLS using a modification of a capsplint model, we found mucosa-protecting effects of BET only for the combination of $1 \%$ SLS and $4 \%$ BET. When the same SLS and BET concentrations were applied to the oral mucosa in the form of a toothpaste, no differences were detected between the SLS-BET and the regular SLS toothpaste. ${ }^{38}$ Thus, the effects of BET on the mucosa-irritating effect of SLS may also depend on solutions or toothpaste components other than SLS. The two SLS pastes used in this study appeared not to be mucosa irritating, and thus it is not surprising we could not find the relieving effects of BET on SLS as demonstrated in the earlier studies. BET in the detergent-free formula, however, appeared to improve the formula with respect to effects on oral mucosa. In the evaluation made at the end of the trial, the BET toothpaste was reported to relieve subjective symptoms of dry mouth twice as effectively as any other test paste. The BET paste was also associated with the lowest VAS scores for lip dryness, the strongest sensation of dry mouth. Thus, BET may have added osmoprotective properties to the pastes as suggested earlier. ${ }^{28}$

\section{Conclusion}

As a summary, all mildly flavoured toothpaste formulas, even those with SLS, were well accepted by the xerostomic subjects, and no adverse effects such as aphtous ulcers were connected with the use of the pastes. Our results suggest that other toothpaste components may be more mucosa-irritating than just SLS, or they enhance the effect of SLS. The detergent-free, BET-containing toothpaste appeared to be associated with the relief of some symptoms of dry mouth. This suggests that oral hygiene product formulas specially designed for xerostomic subjects may benefit from the inclusion of BET. 


\section{References}

1. Ericsson Y, Hardwick L. Individual diagnosis, prognosis and counselling for caries prevention. Caries Res. 1978;12 Suppl 1:94-102. No abstract available.

2. Nederfors T. Xerostomia and hyposalivation. Adv Dent Res. 2000 Dec;14:48-56. Review.

3. Nederfors $\mathrm{T}$, Isaksson R, Mörnstad $\mathrm{H}$, et. al. Prevalence of perceived symptoms of dry mouth in an adult Swedish population-relation to age, sex and pharmacotherapy. Community Dent Oral Epidemiol. 1997 Jun;25(3):211-6.

4. Hochberg MC, Tielsch J, Munoz B, et. al. Prevalence of symptoms of dry mouth and their relationship to saliva production in community dwelling elderly: the SEE project. Salisbury Eye Evaluation. J Rheumatol. 1998 Mar;25(3):486-91.

5. Sreebny LM. Dry mouth and salivary gland hypofunction, Part II: Etiology and patient evaluation. Compendium. 1988 Sep;9(8):630-1, 634-5, 638 passim. No abstract available.

6. Atkinson JC, Fox PC. Sjögren's syndrome: oral and dental considerations. J Am Dent Assoc. 1993 Mar;124(3):74-6, 78-82, 84-6. Review.

7. Konttinen YT, Kontio R, Nordström DC, et. al. Sjögrenin oireyhtymä. Suomen Lääkärilehti 1999;26: 3061-3073.

8. Sreebny LM. Dry mouth and salivary gland hypofunction, Part I: Diagnosis. Compendium. 1988 JulAug;9(7):569-70, 573-4, 576 passim. No abstract available.

9. Backman K, Jonsson R. Oral manifestations associated with Sjögren's syndrome: clinic, diagnosis and treatment. Tandläkartidningen 1988;80:896-902.

10. Sreebny LM. Dry mouth and salivary gland hypofunction, Part III: Treatment. Compendium. 1988 Oct;9(9):716-7, 720-1. No abstract available.

11. Steller M, Chou L, Daniels TE. Electrical stimulation of salivary flow in patients with Sjögren's syndrome. J Dent Res. 1988 Oct;67(10):1334-7.

12. Jensen JL, Barkvoll P. Clinical implications of the dry mouth. Oral mucosal diseases. Ann NY Acad Sci. 1998 Apr 15;842:156-62. Review.

13. Navazesh M, Wood GJ, Brightman VJ. Relationship between salivary flow rates and Candida albicans counts. Oral Surg Oral Med Oral Pathol Oral Radiol Endod. 1995 Sep;80(3):284-8.

14. Papas AS, Joshi A, MacDonald SL, Maravelis-Splagounias L, Pretara-Spanedda P, Curro FA. Caries prevalence in xerostomic individuals. J Can Dent Assoc. 1993 Feb;59(2):171-4, 177-9.

15. Najera MP, Al-Hashimi I, Plemons JM, et. al. Prevalence of periodontal disease in patients with Sjögren's syndrome. Oral Surg Oral Med Oral Pathol Oral Radiol Endod. 1997 Apr;83(4):453-7.

16. Newbrun E. Dentifrices. In: Newbrun E. Cariology. 3rd ed. Chicago, IL: Quintessence, 1989;274-290.

17. Waaler SM, Rölla G, Skjörland KK, et. al. Effects of oral rinsing with triclosan and sodium lauryl sulphate on dental plaque formation: a pilot study. Scand J Dent Res. 1993 Aug;101(4):192-5.

18. Herlofson BB, Barkvoll P. Oral mucosal desquamation of pre- and post-menopausal women. A comparison of response to sodium lauryl sulphate in toothpastes. J Clin Periodontol. 1996 Jun;23(6):567-71.

19. Herlofson BB, Barkvoll P. Oral mucosal desquamation caused by two toothpaste detergents in an experimental model. Eur J Oral Sci. 1996 Feb;104(1):21-6.

20. Lee $\mathrm{CH}$, Maibach HI. The sodium lauryl sulphate model: an overview. Contact Dermatitis. 1995 Jul;33(1):1-7. Review.

21. Agner T, Serup J. Skin reactions to irritants assessed by non-invasive bioengineering methods. Contact Dermatitis 1989;20:352-359.

22. Agner T, Serup J, Handlos V, et. al. Different skin irritation abilities of different qualities of sodium lauryl sulphate. Contact Dermatitis. 1989 Sep;21(3):184-8.

23. Berardesca E, Maibach HI. Sodium-lauryl-sulphate-induced cutaneous irritation. Comparison of white and Hispanic subjects. Contact Dermatitis. 1988 Aug;19(2):136-40.

24. Herlofson BB, Barkvoll P. The effect of two toothpaste detergents on the frequency of recurrent aphthous ulcers. Acta Odontol Scand. 1996 Jun;54(3):150-3.

25. Huang J, Hirji R, Adam L, et. al. Genetic engineering of glycinebetaine production toward enhancing stress tolerance in plants: metabolic limitations. Plant Physiol 2000;122:747-756.

26. Jutila K. A method of reducing the irritating properties of a cosmetic composition. International patent 1991. WO 91/18588. 
27. Jutila K. EPO patent 0531387, 1996.

28. Nicander I, Rantanen I, Lundh Rozell B, et. al. The ability of betaine to reduce the irritating effects of detergents assessed visually, histologically and by bioengineering methods. Skin Res Technol. 2003 Feb;9(1):50-8.

29. Söderling $E$, Le Bell $A$, Kirstilä $V$, et. al. Betaine-containing toothpaste relieves subjective symptoms of dry mouth. Acta Odontol Scand. 1998 Apr;56(2):65-9.

30. Tsamtsouris A, White GE, Clark RE. A comparison between the plaque indices of Silness-Löe and Greene-Vermillion. J Pedod. 1980 Fall;5(1):51-61. No abstract available.

31. Turesky S, Gilmore ND, Glickman I. Reduced plaque formation by the chloromethyl analogue of vitamin C. J Periodontol 1970;41:41-43.

32. Billings RJ, Meyerowitz C, Featherstone JD, et. al. Retention of topical fluoride in the mouths of xerostomic subjects. Caries Res. 1988;22(5):306-10.

33. Sainio EL, Kanerva L. Contact allergens in toothpastes and a review of their hypersensitivity. Contact Dermatitis. 1995 Aug;33(2):100-5. Review.

34. Delattre VF. Factors contributing to adverse soft tissue reactions due to the use of tartar control toothpastes: report of a case and literature review. J Periodontol. 1999 Jul;70(7):803-7. Review.

35. Herlofson BB, Barkvoll P. Sodium lauryl sulfate and recurrent aphthous ulcers. A preliminary study. Acta Odontol Scand. 1994 Oct;52(5):257-9.

36. Healy CM, Paterson M, Joyston-Bechal S, et. al. The effect of a sodium lauryl sulfate-free dentifrice on patient with recurrent oral ulceration. Oral Dis. 1999 Jan;5(1):39-43.

37. Barkvoll P. Considerations concerning the sodium lauryl sulphate content of dentifrices. In: Embery G, Rölla G, eds. Clinical and biological aspects of dentifrices. London: Oxford University Press, 1992; 173-180.

38. Rantanen I, Jutila K, Nicander I, Tenovuo J, Söderling E. The effects of two sodium lauryl sulphate-containing toothpastes with and without betain on human oral mucosa in vivo. Swed Dent J. 2003, 27 (1): 31-34.

\section{Acknowledgements}

We express our gratitude to the National Technology Agency, TEKES, Finland, and the Finnish Dental Society Apollonia, for financial support. We also wish to thank the "Kuivakukat" Association members in the Turku area for their participation in this study.

\section{About the Authors}

\section{Irma Rantanen, DDS}

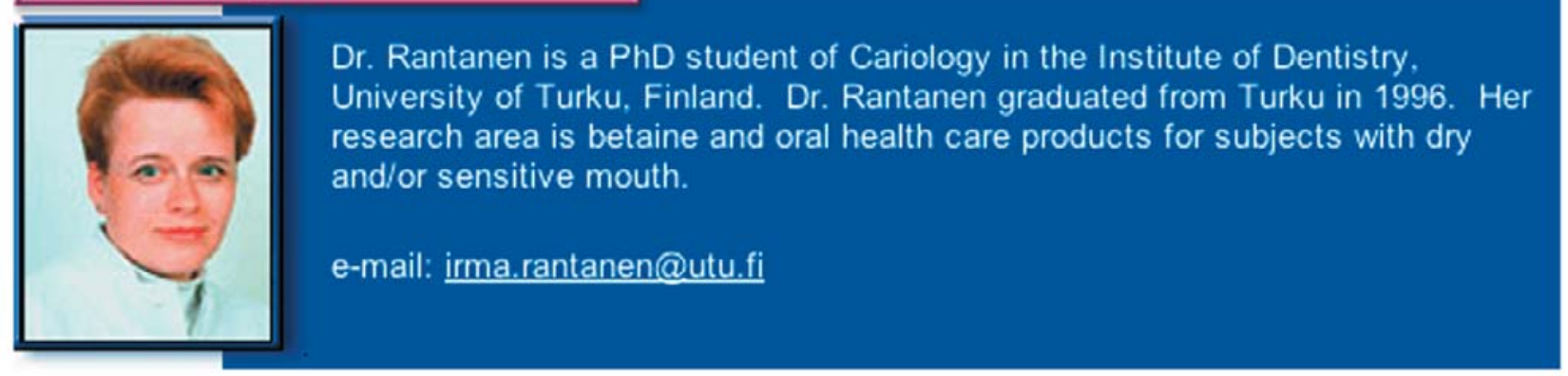




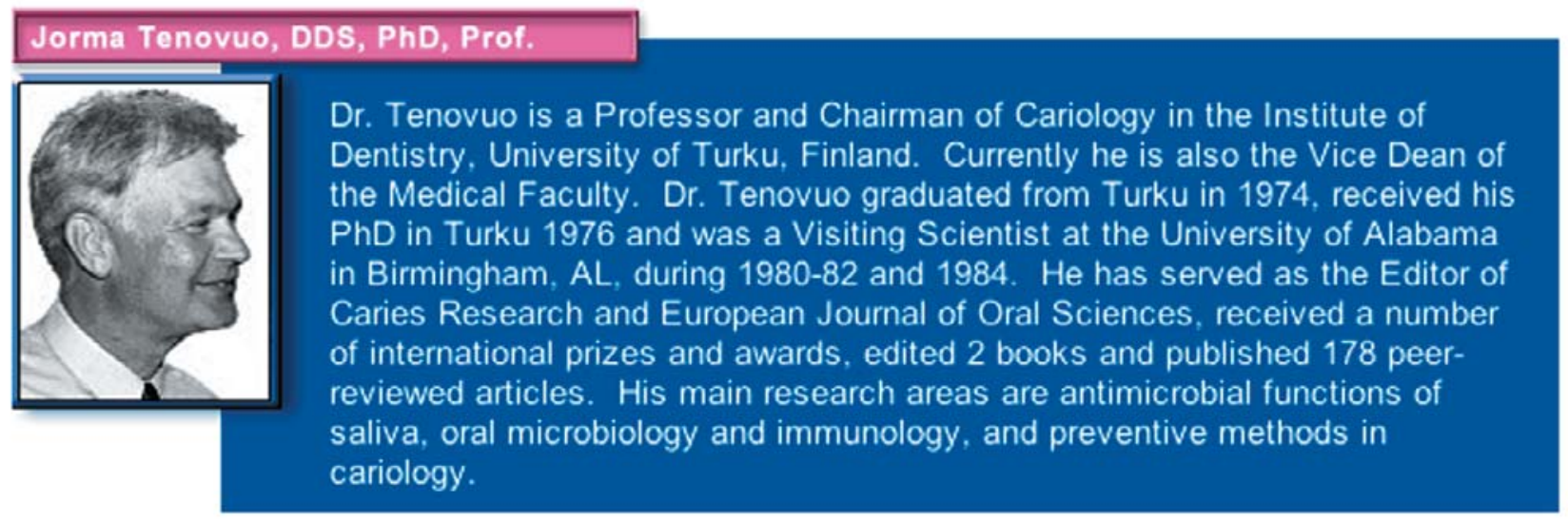

\section{Kaisu Pienihakkinen, DDS, PhD}

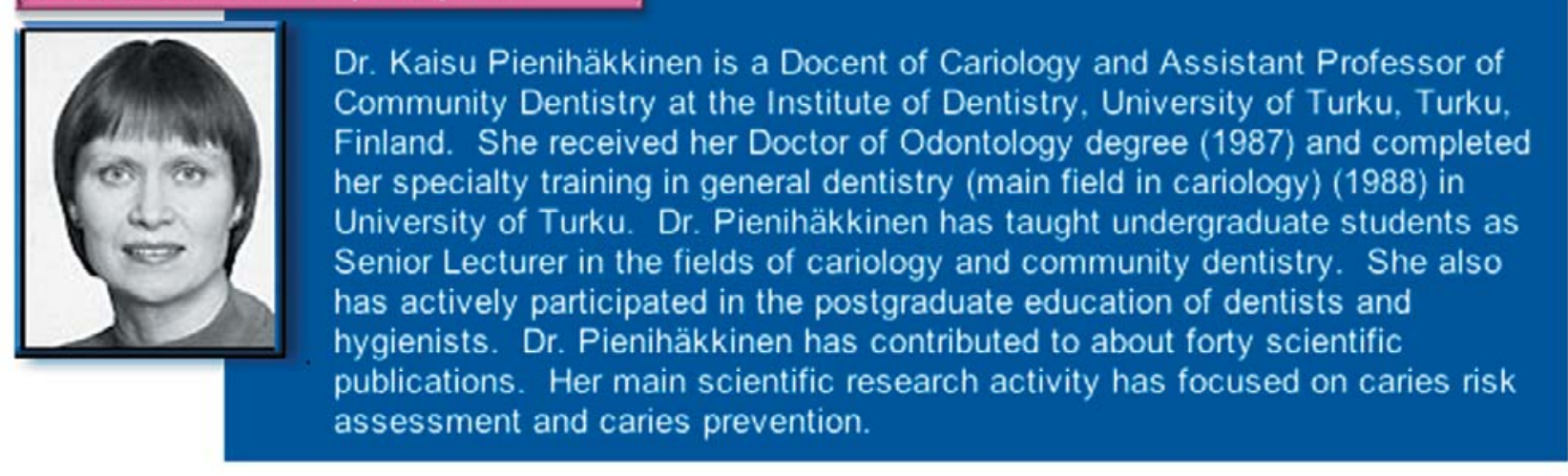

\section{Eva Soderling, PhD, MSc}

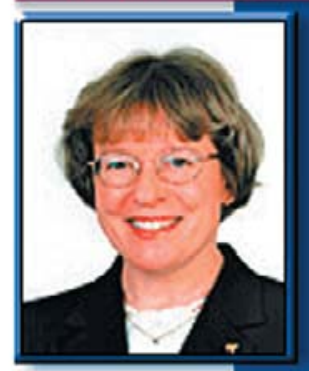

Dr. Eva Söderling is a Senior Lecturer and the Laboratory Manager at the Institute of Dentistry, University of Turku, Turku, Finland. She received her M.Sc. (1975) and Ph.D. (1983) from the University of Turku. She has spent most of her academic career at the University of Turku in various positions, for example as a professor in Oral Biology. She has worked as a visiting researcher both in USA and Canada. Dr. Söderling has published 120 peerreviewed articles and holds several patents. She has given invited lectures in 12 countries, including USA, Canada, Mexico, Brazil, Argentina and Japan. She has also participated in postgraduate education of dentists and dental hygienists. Her recent research activities have focused on effects of xylitol and betaine on oral health. 